\title{
Fiber Art and Its Application in Illustration Creation
}

\author{
Qiduan Chen ${ }^{1, a}$, XiaoJun Tang 2,b \\ ${ }^{1}$ Department of Art and Design, The Jimei university, Jimei , Xiamen,Fujian, China \\ ${ }^{2}$ Department of Art and Design, The Jimei university, Jimei, Xiamen,Fujian, China \\ a1140751800@qq.com \\ b*657819714@qq.com
}

\begin{abstract}
The fascination of fiber material modeling representation is that such material has various ways of expression since everyone can create their own rules and techniques for painting. They even can set different creation principles for each work, and each characteristic and element is of the designer's unique thoughts, like telling a story through this screen. This is quite attractive to researchers, and the resulting research are important in guiding the creation of model representations using fiber material. This research will collect and analyze important contemporary works so as to understand their forms and representations. The research methods are mainly to analyze ways of fiber material modeling and representation; dissect creation characteristics of the fiber material; and interpret the characteristics, representation ways, and creation methods by analyzing the use of the fiber material in creating illustrations. We expect to provide a reference for fiber material modeling representation in creating illustrations.
\end{abstract}

Keywords: fiber materials, fiber art, illustration design

\section{INTRODUCTION}

Fiber materials can be presented in various ways to create abundant modeling expressions. Fiber artist Lin Lecheng (2015) stated that "no artistic language can be so rich and colorful with such cordial and approachable meanings.[1]", which attracts the attention of the researcher, and the research results are regarded as of important guiding significance for the creation of fiber material modeling expression. The researcher extensively collected the data of the expressive art of fiber material in various countries, and observed its design and characteristics suitable for the demands of modern design. Since the residents of modern metropolis are surrounded by images and information, the application of illustration is extensive in current era, and its development trend and artistic style must correspond to modern thinking consciousness, cultural values and commercial needs. The performance properties of fiber materials laid solid foundation for illustration to enhance visual effects, bringing innovation in illustration design language and medium.

Based on the above background and incentives, the researcher summarized the characteristics of fiber material expression art through literature review, and analyzed the basis of the application of fiber materials in illustration creation. Through the analysis of contemporary important fiber illustrations, this paper interprets the characteristics, expression techniques and creation methods of fiber materials in illustration creation, and sums up the ideas and suggestions of fiber materials used in illustration creation, to provide reference for the subsequent creation of fiber materials in illustration works.

\section{THEORETICAL REVIEW AND ANALYSIS}

Fiber art is an art category based on fiber materials with technology as the means, so the literature review mainly consists of four aspects including historical background, materials, texture and techniques of fiber art.

\subsection{Historical background}

There are abundant historic records of fiber art, which is rooted in the manual handicraft formed by artificially processed fiber raw materials. Shi Hui and Shan Zeng (2007) discussed the historical background of fiber art in detail[2].

The expressive art of fiber materials closely correlated to tapestries in the West. Woven tapestries appeared in Egypt and Babylon as early as about four 
millenniums ago. Egyptians at that time already acquired relatively advanced linen tapestry technology, leaving behind the oldest woven tapestries in the world. In the 13th century, fiber art was mostly represented by tapestries with legends and biblical stories as themes in Europe. Goblin weaving technique, which originated in Paris, France, taking warp and weft as weaving structure, was the representative of European tapestries at that time. In those days, the style of fiber art was only limited to imitating paintings, making this traditional craft began to decline. In 1919, "Bauhaus School" was founded, which introduced weaving art in formal education for the first time. It advocated the teaching ideology of "the unity of art and technology" in education, started the exploration of modern concepts in fiber art education, and ushered in the modernization process of fiber art. Paul Klee taught on form and color in Bauhaus, where weaving education was deeply influenced by his artistic style. Anni Albers, who once taught in Bauhaus, enjoyed a high reputation in Europe for her abstract and groundbreaking works in tapestry design. Jean Lurçat was a reviver and innovator of traditional French tapestries, who founded the first "CITAM and the Lausanne International Tapestry Biennials" in 1962. Fiber art began to break the traditional form of imitating paintings with fiber materials, gradually developed into a truly independent art, and promoted the communication between Chinese and Western fiber artists, opening new avenues for fiber art.

Social movements also posed far-reaching influence on the aesthetic development of fiber art. For instance, post-modern artistic thoughts and feminist movements have all promoted the development of fiber art[3]. Fiber art has experienced a lengthy transformation and has precipitated strong cultural connotations. As time flies, it has been continuously facilitated with new elements and starts to possess ample forms and functions.

\subsection{Materials}

Fiber art is based on material as its form of expression. It breaks through the traditional definition of material, re-recognizes material, excavates the potential form of material, and obtains innovative visual effects. Meng Zhihan (2018) thinks that fiber art is a type of material art, in which creators boldly excavate, explore and integrate different fiber materials[4]. The elements and applications of fiber art are no longer simplex, but gradually rejuvenate and develop into a diversified pattern. Materials related to fiber art can be classified as follows[5].

\subsubsection{Natural fiber materials}

Natural fiber materials are derived from natural materials originally existing in nature and formed through simple processing and treatment. They can be divided into plant fiber and animal fiber. Plant fiber materials comprise cotton, hemp, grass, bamboo, rattan, etc., while animal fiber is obtained from animals, mainly including fur, silk, down, etc. Natural fiber was first recognized and adopted by human beings. Because it originates from the life elements of nature, so it has the closest relationship with human beings. In fiber art, natural fiber materials have always occupied an important position and are still the main raw materials used in fiber art creation.

\subsubsection{Artificial fiber materials}

Chemical fiber materials are obtained through complex chemical refining and technological processing. The polymer compounds expand the scope of fiber materials and show unique properties. They can be mainly divided into artificial fibers and synthetic fibers, including nylon, polyester, polypropylene, ethylene, etc. Technological innovation has produced chemical fiber materials. Compared with natural fiber materials, they own stronger plasticity, heat resistance and insulation properties, making the creation of fiber art more prosperous and diverse. To sum up, materials are an important element of fiber art, and with the pace of the times, the range of choices has been continuously broadened.

\subsection{Texture}

In the creation of fiber art, the expression of texture plays a key role and is an indispensable form. Xiu Yuhong (2018) believes that the expression of texture cannot be bound by any materials or techniques, which is the carrier of expression theme of fiber art. Artists can create works more flexibly[6]. The texture of fiber materials has different sense of quality and volume caused by many aspects, among which there are two main types of expressions. The first type is the natural texture of the material itself. In fiber art, the combination of different material textures, such as rigidity and tenderness, transparency and turbidity, smoothness and concave-convex, softness and roughness, can lead to visual ups and downs and changes in psychological feelings.

The second type is to make full use of the tissue structure of fiber materials to change the conditions and appearance characteristics of texture. Different tissue structures of the same material will form different texture senses. Warp-weft weaving structure, through the interweaving combination and arrangement of fiber materials, can produce texture which is layered. Plain weave, satin weave and twill weave are the basic 
warp-weft weaving structures. With the improvement of weaving techniques, innovative effects such as herringbone pattern, linked-pearl pattern and triangular pattern have also emerged. Free tissue structure allows materials to get rid of the shackles of warp and weft, and can achieve texture effects different from warp and weft structure by free expression methods such as continuous winding, collage, folding and hanging on the basis of the original materials. It can be seen that texture can generate various visual aesthetic feelings in fiber art.

\subsection{Color}

Color blends into the materials and forms of works, which is a necessary element in the expression of fiber art and an important starting point for interpreting fiber art. Wu Shengjie (2015) thinks that the expression of color in fiber art is an essential means to convey the creator's thoughts and render the theme atmosphere, and he summarizes the expression of color in fiber art into two aspects[7]. The first aspect is the inherent color language of the material, which is expressed by its own appearance. The primary colors of the material can bring people a plain feeling. Secondly, dyeing, electroplating, coating, covering and other artificial methods are adopted to change the inherent color of materials and produce some subjective colors, thus further enriching the author's creative theme. Therefore, color has infinite space to play in fiber art.

\subsection{Techniques}

Related techniques of fiber art have added unique forms and charm to its creation. The techniques of fiber art are derived from traditional handicrafts and are constantly updated with technological advancement. According to Zhao Na (2010), the techniques of fiber art have experienced the following evolution forms: common traditional expression techniques including weaving, printing and dyeing and embroidery; with the development of the times, production techniques integrated with science and technology are introduced in fiber art on the basis of traditional techniques. For instance, in addition to traditional techniques such as batik, missing printing, tie dyeing, hitch weaving, knitting embroidery and knitting embroidery, digital approaches such as computer inkjet printing, digital printing and dyeing, and computerized embroidery have been employed[8]. Meanwhile, according to the needs of materials and forms of expression, new expression techniques such as barbola, stitching, tearing, folding and stacking also have been developed in fiber art. In light of this fact, the techniques of fiber art, like the texture of its materials, are constantly developing towards diversification.

\subsection{Illustrations made by traditional graphic techniques and illustrations made by fiber material expression techniques}

Pope (1948) made a quite incisive annotation on illustration art: "Art works with strong descriptive thoughts and feelings[9]." The evolution of illustration forms is inseparable from the drawing media and production methods. Fiber art has brought new modeling language and expression tools, enriched illustration expression techniques, expanded expression space and strengthened the compatibility with other graphic techniques. The following documents compiled in Table 1 sort out the differences between illustrations made by traditional graphic techniques and those made by fiber material expression techniques.

Table 1 Difference between illustrations made by traditional graphic techniques and illustrations made by fiber material expression techniques

\begin{tabular}{|c|c|}
\hline \multicolumn{2}{|c|}{ Illustrations made by traditional graphic techniques } \\
\hline Media & $\begin{array}{l}\text { The media materials of traditional graphic techniques } \\
\text { include pencil, marker, acrylic, crayon, ink painting, } \\
\text { watercolor and other painting tools. With the advent of } \\
\text { the Internet era, digital production software has also } \\
\text { been introduced as a medium for creative performance. }\end{array}$ \\
\hline Retouching & $\begin{array}{l}\text { It is necessary to master the technical application of the } \\
\text { media used, grasp the style of picture expression and } \\
\text { all aspects of painting, including color, composition, } \\
\text { contrast, space and other fields. }\end{array}$ \\
\hline Application & $\begin{array}{l}\text { It is mainly applied in painting, printing media, web } \\
\text { pages and other media in plane form. }\end{array}$ \\
\hline \multicolumn{2}{|c|}{ Illustrations made by fiber material expression techniques } \\
\hline Media & $\begin{array}{l}\text { Due to the diversity of fiber materials, the use of media } \\
\text { in its expression techniques has rich and diverse } \\
\text { characteristics. Each kind of media with different } \\
\text { expressiveness can give people different aesthetic } \\
\text { feeling. }\end{array}$ \\
\hline Retouching & $\begin{array}{l}\text { In addition to mastering the basic elements of } \\
\text { retouching pictures in graphic techniques, it is also } \\
\text { necessary to consider the collocation of color, texture } \\
\text { and quality among materials, as well as the } \\
\text { combination effect of materials and technological } \\
\text { means, including the combination of various production } \\
\text { means and materials; The same material can be } \\
\text { expressed with various techniques, while a single } \\
\text { technique can express a variety of materials. }\end{array}$ \\
\hline Application & $\begin{array}{l}\text { The graphic creation on fiber textile dominated in the } \\
\text { early days. Later, in addition to the simplex plane } \\
\text { expression mode, three-dimensional and even } \\
\text { multi-dimensional expression methods emerged, } \\
\text { showing the innovative development of various form } \\
\text { applications. }\end{array}$ \\
\hline
\end{tabular}

\section{CASE STUDY}

This paper selects the Hungarian artist Agnes Herczeg's fiber illustration creation as a case. She has been studying embroidery and lace making techniques for many years and has a solid foundation in fiber art creation. The size of her works usually ranges from 5 $\mathrm{cm}$ to $18 \mathrm{~cm}$ high, with complicated and ingenious patterns, and fine and rich textures. She can handle the contrast of softness and toughness, stretching and tightness of embroidery with ease, and vividly show the 
charm of nature. Both the creative elements and the expression forms of patterns in her works are unique and innovative, which is a territory that other fiber illustrators seldom dabble in. Therefore, this paper takes her works as study cases to analyze her application forms and processes of fiber material illustrations from three aspects: design intention, materials and tools and implementation steps.

\subsection{Design Intention}

The design intention of Agnes Herczeg is closely associated with her living environment, interests and experiences. She lives near the Danube River, enjoys walking in nature, often spends time collecting beautiful wood and branches, and integrates the unique and interesting shapes of natural objects into her works. From an early age, she showed her familiarity with and love for simple life. She was inspired by the beautiful environment and took it as the theme for creation, hoping to show the ordinary life style vividly through artistic forms. Therefore, her illustration theme usually revolves around life scenes, pastoral scenery and female images, displaying a quiet atmosphere and conveying the connection between women and nature.

\subsection{Materials and Tools}

Each fiber material has a texture different from other materials, while the use of different fiber materials in illustration creation can produce different aesthetic feelings. The materials adopted by Agnes Herczeg have the following characteristics: the natural fiber materials used in the main part include lace, linen, cotton thread, etc., as well as chemical fiber materials such as metal thread and nylon. Lace has fine and soft texture, beautiful luster and less granular sensation, so works made of lace fiber will bring meticulous and excellent aesthetic feeling to people. Linen is not easy to rot, tough and fresh, rough in texture, and can generate decorous visual impression. Cotton thread has the characteristics of good tensile property, high elasticity and strong processability. These materials are common natural fiber materials, which can convey a plain and cordial feeling peculiar to natural materials, echoing the theme atmosphere of Agnes Herczeg's natural illustrations. Nylon and metal thread are hard and tough, and the use of these chemical fiber materials with high molding performance can create clean-cut and firm structures and outlines for picture elements. Agnes Herczeg also used branches, ceramic chips, stones, clay, coconut shells and other physical materials to make the frame, which is one of the features of her works. Natural material has its inherent decoration ability and connotation, which enhances the unique feeling and natural atmosphere of each work and produces aesthetic value of specific significance. Other auxiliary tools include crochet, sewing needle, sketching tools, dyeing pigment, coloring brush, etc., which are used to assist the completion of the whole picture.

\subsection{Implementation Steps}

The creation steps of illustration represented by fiber materials involve various ideological contents. The works of Agnes Herczeg follow rigorous implementation steps. First of all, rigorous layout is carried out according to the theme of creation, including the composition and color of the design, as well as the sequence and density of weaving. After repeated experiment of material, the creation form is determined before formally entering the implementation stage of creation. The first step of creation is to sketch the outline on thick paper. According to the drawn draft, the outline is fixed with metal thread, and is then the expressed by techniques. In order to strengthen the expressive force of materials and enrich the sense of layering, Agnes Herczeg adopted a combination of weaving, pasting, sewing, hanging, intertwining and other techniques. After the main form was completed, the thread tail was removed, the seam between the thread end was hidden, then the paper background was removed, and every small part of the picture was thoroughly cleaned. In order to pursue the harmonious matching of colors, she used water-based highly saturated pigments to dye the fiber materials, and carefully colored the main body layer by layer with small brushes. Finally, the natural objects were cut, polished and painted to form a frame, and the main body shape was fixed to the made frame by stitching techniques, thus realizing the creativity and integrity of the work[10].

\section{DISCUSSION AND REFLECTION ON WORKS}

The illustration works of Agnes Herczeg will be discussed in detail in the following passage, and relevant thoughts and suggestions on the application of fiber materials in illustration will be summarized from four aspects: the expression of design concept, the selection of materials, the use of match colors and the presentation of drawing techniques.

\subsection{Expression of design concept}

Before creating works, it is necessary to conceive ideas and think about how to maximize the presentation of personal inspiration and design concept. The expression of design concept is a crucial link in illustration works. Agnes Herczeg combines the concept of the work with the visual aesthetic feeling expressed by the materials. Female face series is one of her unique series works (as shown in Figure 1). In this series of works, different types of female facial expressions are created, for example, a woman with drooping eyes and 
meditating, a lady looking straight, and a young girl thinking while cupping her cheeks. Agnes Herczeg employed exquisite lace beauty to convey the femininity and rhythm of women, adopted saturated and rich textures to reflect novel facial features of women, and ingeniously added the shape of branches into the modeling of characters, setting off the theme emotion between nature and women.

The researcher believes that in the expression of the concept of fiber material illustration, the characteristics of material texture can be fully utilized to increase the embodiment of ideas, and the fiber material expression art can provide more approaches and inspiration for the expression methods of illustrators' ideas.

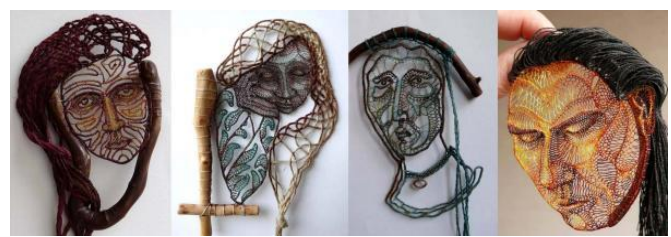

Figure 1 Female faces series of Agnes Herczeg

\subsection{Selection of Materials}

Material is an important constituent of fiber illustration, and the correct selection and collocation of fiber materials can make illustrations demonstrate various artistic effects. In Agnes Herczeg's works with plant landscape as the theme (as shown in Fig. 2), the characteristics of different materials work in concert with the relevant elements. The translucence of water flow outlined by the slender metal threads, exquisite plants created by delicate lace and the ancient reef made by coarse coconut shells, the matching of materials forms the contrast between surface and line, reality and virtuality, coarseness and fineness. Reasonable selection and treatment of materials enable her illustrations to demonstrate excellent environmental aura and artistic effects.

The researcher believes that in the selection of fiber materials for illustration, the creator should have a full grasp of the fiber material from its external features to its internal material characteristics, such as its glossiness, dryness, plasticity, hardness, thickness, etc., and choose materials according to the requirements of the expression form. Then, by taking materials as the breakthrough point of creation, the materials selected should be repeatedly scrutinized, including thinking on the density and arrangement, superposition and repetition, interweaving and interspersing of materials, which is expressed as the creation based on the groping, extracting, decomposing and reconstructing of materials to fully explore the possibilities of various materials, so that the works can fully display the optimal artistic effect. With the constant modernization and diversified development of fiber materials, creators can continuously take advantage of their richness to provide more innovation and enlightenment for the visual language and composition style of illustrations.

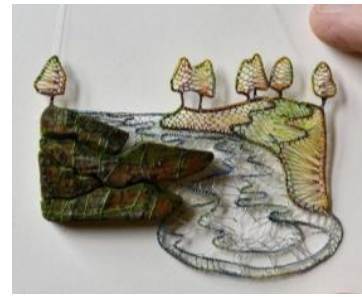

Figure 2 Plant landscape theme works of Agnes Herczeg

\subsection{Application of Match Colors}

Color is an essential factor for viewers to perceive works. Reasonable use of color can enhance the appeal of works. In fiber material illustrations, color matching is one of the formal languages that cannot be ignored by creators. As shown in Figure 2, the color matching is fresh and harmonious, and the color tone is unified. Most of the colors are blue, green, brown and orange, which are common natural elements, creating an atmosphere and enjoyment of natural beauty. Through the later dyeing treatment, the colors of plant elements show subtle color changes along with the structure constructed by threads, so that the picture elements demonstrate a sense of space and volume, and achieve overall coordination when looking from a distance and rich and changeable color effects when looking closely, skillfully revealing the gorgeous plant colors in nature.

In light of the works of Agnes Herczeg, the researcher is inspired on the application of color matching in fiber material illustrations. The color of illustrations expressed by fiber materials is blended with material and form, possessing two kinds of expression involving the color of the material itself and the artificially modified color. Therefore, the researcher thinks that the overall color gamut of the materials used should be considered first in creation and application, the color selection of materials should be consistent with the creative concept. Then, according to the characteristics and modeling needs of materials, the color matching and contrast between materials should be grasped, and the rhythm and primary-secondary relationship should be determined according to the area of colors, thus reflecting the fluctuation of content and the distance between space. Furthermore, attention should be paid to the interaction between colors and textures and the blending of colors and shapes. The expression method of artificial color can also enhance the sensation of layering of the picture. The color effect of fiber material expression art can produce a variety of collisions and expressions, which is more plastic and open. When applied to illustration, it can endow the pictures with more highlights. 


\subsection{Presentation of Drawing Techniques}

The drawing techniques of fiber material illustration is miscellaneous and unlimited, and the reasonable presentation of techniques determines the richness of the composition style and visual language of the work. Each work produced by Agnes Herczeg is committed to breaking technical boundaries. As shown in Fig. 3, the waves are transformed into semitransparent hollowed-out texture effect by adopting several comprehensive techniques such as needlepoint lace, bobbin lace, sewing and intertwining, giving off unique permeability and stereoscopic perception. Through proper arrangement and combination, a novel artistic expression form of the waves is created, reflecting the beauty of rhythm and modernity, attracting viewers with eye-catching expression, which enhances the ornamental value and interestingness of the illustration itself. The researcher believes that in the presentation of fiber material illustration drawing techniques, materials can be decomposed and reorganized, and more available collocation methods of materials and techniques can be explored. The endless production techniques in the expression art of fiber material can generate new visual effects for illustration, thus promoting the expression tension in illustration creation.

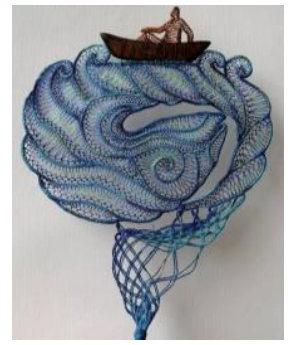

Figure 3 Wave theme works of Agnes Herczeg

\section{CONCLUSIONS}

Fiber art possesses an expansive expression space, presenting diversified artistic charm. Its application in illustration creation brings not only novel techniques and materials, but the characteristics required by the art of the new era and the new way of thinking in creation. The potential of fiber material illustration is far more than what can be seen currently. Creators can effectively design fiber materials by taking advantage of their modeling expression, which can provide infinite innovation possibilities to illustrations occupying the market of the visual age. This research topic is a discussion and reflection on the blending of traditional graphic illustration art and fiber art categories. The researcher further grasps the characteristics and manifestations of fiber art, explains, analyzes and ponders over the artistic forms presented by the application of fiber art in illustration design, summarizes the relationship between creation and application forms, which provide inspirations for the researcher to study the application of fiber materials in modern illustration creation in the future. The follow-up study will integrate the reflection and understanding of fiber material expression art into the practice of illustration creation.

\section{REFERENCES}

[1] Lin Lechen, The Applied Beauty of Fiber Art, Architecture and Culture, (04)(2015)77-79.

[2] Shi Hui, Dan Zen, Research on Modern Fiber Art, New Art, (04)(2007)50-62.

[3] Claire C. Park, Appropriation, Transformation and Contemporary Fiber Art: An Artist's Perspective, University of Nebraska - Lincoln, 2004.

[4] Meng Zhihan, Modern Fiber Art Materials and Texture Research, Shenyang Ligong University, 2018.

[5] Cao Huiqin, Material Language of Modern Fiber Art, Shanghai Arts and Crafts, (01)(2005)78-79.

[6] Xiu Yuhong, On The Beauty of Texture in Fiber Art,JiLin University Of The Arts, 2018.

[7] $\mathrm{Wu}$ Shengjie, Research on Color Expression in Modern Fiber Art, China Academy of Art, 2015.

[8] Zhao Na, Language Expression Form and Innovation of Fiber Art, Wuhan Textile University, 2010 .

[9] Pope, A, Teaching the Theory and Practice of Drawing and Painting, College Art Journal, 7(3) (1948) 164-168.

[10] Jane. Agnes Herczeg:Thoroughly modern lace. https://www.textileartist.org/agnes-herczeg-thoroug hly-modern-lace/ 